\title{
ISOLASI DAN IDENTIFIKASI SENYAWA YANG BERSIFAT ANTIBAKTERI DAN TOKSIK DALAM TUMBUHAN ILER \{Coleiis scutellarioides [L.] Benth)
}

\author{
Dionisius Tungga '), I Made Dira Swantara ${ }^{2}$ ), Yenni Ciawi ${ }^{3}$ ) \\ 1)FakuItas Pertanian Universitas Flores, 2)Fakultas MIPA Universitas Udayana, 3)Fakultas Teknik \\ Universitas Udayana \\ dion_uniflor@yahoo.co,id
}

\begin{abstract}
The Isolation and Identification of Antibacterial and Toxic Compound on Coleiis scutellarioides [L.] Benth.

The isolation and identification of antibacterial and toxic compound on Coleiis scutellarioides [L.] Benth. has been conducted. The extraction applied was maceration method using ethanol $85 \%$. The ethanol extract then partitioned using three kinds of solvents namely n-hexane, cloroform, ethilacetate respectively. The most toxic and active antibacterial extraction was separated by chromatography column with n-hexane : cloroform as the mobile phase. Identification of the active isolate was conducted by gas chromatography - mass spectroscopy with the aim of'Wiley 229.L database.

Toxic test and antibacterial activity test showed that $\mathrm{FB}_{2}$ was proved to be the most toxic and active antibacterial one. The most toxic and active antibacterial fraction of $\mathrm{FB}_{2}$ showed a retardation area of $66,98 \mathrm{~mm}^{2}$ to Micrococcus luteus and $54,43 \mathrm{~mm}^{2}$ to Eschericia coli, and $\mathrm{LC}_{50}$ at $90,72 \mathrm{ppm}$. Gas chromatography - mass spectroscopy data show that the FB2 fraction contains 4 compounds namely palmitat acid $(24,41 \%)$; stearat acid (19,53\%); 9-oktadekenamida (22,95\%); and esther dioktyl hexadioat $(33,11 \%)$ -
\end{abstract}

\section{Keywords : Isolation, Identification, Antibacterial compounds, Toxic compounds}

\section{PENDAHULUAN} Penggunaan tumbuhan obat secara
tradisional semakin diminati karena pada
umumnya tidak menimbulkan efek samping
seperti halnya obat-obatan hasil sintesis. Salah
satu tumbuhan obat yang sudah sering
digunakan secara tradisional dan juga tercatat di
dalam usada Taru Premana adalah iler \{Coleus
scutellarioides [L.] Benth). Iler berasal dari
Asia Tenggara dan umumnya ditemukan pada
tempat-tempat yang lembab dan terbuka. Corak,
bentuk dan warna iler beraneka ragam, tetapi
yang berkhasiat obat adalah yang berwarna
merah kecoklatan.

Tumbuhan iler secara tradisional banyak digunakan sebagai obat wasir, obat bisul, obat demam nifas. obat radang telinga, dan obat haid tidak teratur. Selain itu juga digunakan sebagai obat abses, borok, luka bernanah, keputihan, kencing manis, sembelit, dyspepsia, cacingan, gigitan ular, dan serangga beracun. Di samping itu senyawa kimia polar yang terkandung dalam tumbuhan iler diduga dapat menghambat pertumbuhan sel leukimia.

Penelitian terdahulu yang dilakukan oleh Darma, 2005, terhadap ekstrak kental etanol, menunjukkan bahwa ekstrak kental ini bersifat antibakteri yang diuji terhadap bakteri Gram positif (Micrococcus luteus) dan Gram negatif \{Eschericia coli) yang menghasilkan daerah hambatan dengan diameter berturut-turut $3,8 \mathrm{~mm}$ untuk Micrococcus luteus dan $1,1 \mathrm{~mm}$ untuk Eschericia coli.

Menurut Heryana, 1987, yang terdapat dalam Pusat Data dan Informasi-Persi tentang obat tradisional, senyawa kimia yang terkandung dalam tumbuhan iler adalah flavonoid, alkaloid, saponin dan minyak atsiri. Selain itu tumbuhan iler juga mengandung tanin, lemak, phytosterol, kalsium oksalat, dan polisakarida.

Penelitian ini bertujuan untuk Untuk mengetahui senyawa atau gabungan senyawa yang bersifat antibakteri dan/ atau bersifat toksik tersebut.

\section{BAHAN DAN METODE}

\section{Bahan}

Bahan yang digunakan dalam penelitian ini adalah serbuk daun tumbuhan iler yang diambil dari desa Palean, kecamatan Baturiti, kabupaten Tabanan, Bali. Disamping itu digunakan bahan kimia seperti etanol, kloroform, asetat anhidrat, etilasetat, n-heksana, akuades, natrium hidroksida, asam klorida, magnesium, asam sulfat, dan asam klorida.

Alat

Alat-alat yang digunakan dalam penelitian ini adalah : seperangkat alat gelas, penguap putar vakum, kertas saring, blender, pipet tetes, pipet mikro, pipet volume, botol tempat sampel, 
seperangkat alat KLT, seperangkat alat kromatografi kolom, lampu UV, cawan petri, seperangkat alat kromatografi gas - spektroskopi mnssn.

\section{Cara Kerja}

Sebanyak 300 gram serbuk kering tumbuhan iler dimaserasi dengan etanol $85 \%$ dalam air. Ekstrak etanol yang diperoleh disaring kemudian residunya dimaserasi lagi dengan pelarut yang sama. Hal ini dilakukan sampai 3 kali pengulangan. Filtrat etanol yang diperoleh kemudian diuapkan sehingga menghasilkan ekstrak kentai etanol. Terhadap ekstrak kentai etanol ini dilakukan uji bioaktivitas antibakteri dan toksisitas. Kemudian ekstrak kentai ini dilarutkan ke dalam 200 inL air. Ekstrak air ini dipartisi dengan n-heksana (3 x $50 \mathrm{~mL}$ ) lalu dipisahkan dan lapisan n-heksana diuapkan, sehingga diperoleh ekstrak kentai n-heksana (EH). Residu (lapisan air) dipartisi dengan kloroform (3 x 50 $\mathrm{mL}$ ), lalu dipisahkan dan lapisan kloroform diuapkan sehingga menghasilkan ekstrak kentai kloroform (EK). Lapisan air dipartisi kembali dengan etilasetat (3 x $50 \mathrm{~mL})$, lalu dipisahkan dan lapisan etilasetat diuapkan sehingga diperoleh ekstrak kentai etilasetat (EE).

\section{Pemisahan dan Pemurnian}

Terhadap ketiga ekstrak yang diperoleh (EH, EK, dan EE) dilakukan uji bioaktivitas antibakteri dan uji toksisitas. Ekstrak yang menunjukkan aktivitas yang paling positif, selanjutnya difraksinasi menggunakan kromatografi kolom dengan eluen yang sesuai berdasarkan hasil KLT. Kecepatan alir eluen diatur kira-kira $3 \mathrm{~mL} / 5$ menit. Eluat ditampung setiap $3 \mathrm{~mL}$ dalam wadah. Proses kromatografi kolom dihentikan setelah semua metabolit diperkirakan keluar dari kolom. Terhadap masing-masing eluat pada botol penampung dilakukan pemisahan dengan KLT menggunakan eluen yang sesuai, kemudian nodanya dideteksi. Eluat yang menunjukkan pola noda yang sama digabungkan sehingga diperoleh beberapa fraksi. Semua fraksi yang diperoleh diuji bioaktivitas antibakteri dan toksisitasnya sehingga mendapatkan fraksi yang paling aktif. Terhadap fraksi yang aktif tersebut dilakukan uji kemurnian menggunakan metode KLT dengan menggunakan berbagai sistem eluen. Jika fraksi tersebut belum murni, maka dilakukan pemurnian menggunakan metode kromatografi kolom atau KLT preparatif sampai diperoleh fraksi aktif yang relatif murni. Fraksi yang aktif dan relatif murni tersebut diidentifikasi menggunakan kromatografi gas spektrometri massa.

\section{Uji Bioaktivitas Antibakteri}

Uji aktivitas antibakteri untuk senyawa hasil ekstraksi dilakukan melalui dua tahap, yakni sebagai berikut :

\section{a. Pembuatan Suspensi Bakteri}

Sebanyak satu ose biakan murni bakteri uji diinkubasi dalam media kaldu nutrisi sebanyak 50 $\mathrm{mL}$ dan dimasukkan ke dalam Erlenmeyer. Biakan ini kemudian diinkubasi pada shaker pada temperatur kamar selama 12 jam. Selanjutnya biakan dapat digunakan dalam uji antibakteri.

\section{b. Uji Aktivitas Antibakteri}

Media padat yang berisi bakteri disiapkan dengan cara memipet $0,5 \mathrm{~mL}$ suspensi bakteri yang dimasukkan ke dalam media nutrient cigar steril yang sudah dicairkan pada temperatur $40^{\circ} \mathrm{C}$. Campuran tersebut kemudian digoyang untuk memperoleh suspensi bakteri yang homogen, kemudian dituangkan ke dalam cawan petri steril dan didiamkan sampai membeku. Setelah beku, agar dilubangi dan ke dalam masing-masing lubang dimasukkan sampel sebanyak $40 \mathrm{uL}$ lalu didiamkan selama 24 jam pada suhu $37^{\circ} \mathrm{C}$, sebagai kontrol digunakan pelarutnya. Dalam uji ini hasil positif ditandai dengan terbentuknya zona bening di sekitar lubang sampel yang menunjukkan adanya penghambatan pertumbuhan bakteri.

\section{Uji Toksisitas}

Pengujian dilakukan terhadap ekstrak dan fraksi yang diperoleh. Mula-mula dibuat media untuk larva Artemia salina L. dengan cara menyaring air laut secukupnya. Air laut dimasukkan ke dalam akuarium yang dibagi menjadi dua bagian. Satu bagian dibuat gelap dengan menutupnya dengan kertas hitam. Telur Artemia salina L. diletakkan secukupnya pada bagian yang gelap dan dibiarkan selama 48 jam sehingga telur menetas dan siap digunakan untuk pengujian. Masing-masing fraksi ditimbang sebanyak $20 \mathrm{mg}$ dan dimasukkan ke dalam gelas beker kemudian dilarutkan dengan $2 \mathrm{~mL}$ pelarut. Dari larutan itu diambil sebanyak $500 \mathrm{uL}, 50 \mathrm{uL}$, 5 uL kemudian masing-masing dimasukkan ke dalam tabung reaksi, dan pelarutnya diuapkan selama 48 jam. Ke dalam masing-masing tabung reaksi dimasukkan sedikit air laut, 50 (iL dimetilsulfoksida (DMSO), 10 ekor larva udang, dan setetes larutan ragi, kemudian ditambahkan air laut sampai volume $5 \mathrm{~mL}$, sehingga mencapai konsentrasi 1000. 100, dan 10 ppm. Juga dibuat konsentrasi 0 ppm sebagai kontrol. Masingmasing tabung reaksi ditutup dengan kertas 
aluminium foil dan dilubangi sedikit. Setelah 24 jam dilakukan pengamatan terhadap kematian larva Artemici scilina L. dan jumlah larva yang mati dicatat.

\section{Kromatografi Kolom}

Setelah diperoleh fase gerak yang sesuai dari kromatografi lapis tipis, pemisahan selanjulnya adalah dengan kromatografi kolom. Fase diamnya adalah silika gel G 60 dan fase geraknya adalah pelarut terbaik hasil analisis kromatografi lapis tipis. Silika gel yang telah dikeringkan dalam oven ditambahi fase gerak sehingga menjadi bubur kemudian dimasukkan dalam kolom yang telah berisi fase gerak. Proses penambahan silika gel ke dalam kolom dihentikan setelah silika gel sampai tanda batas yang ditentukan. Selanjutnya kolom dielusi terus sampai kerapatan kolom homogen. Sampel yang akan dipisahkan ditambahkan di atas permukaan silika gel. Pada saat semua sampel masuk ke dalam fase diam dalam waktu yang bersamaan kolom ditambahi fase gerak. Eluat ditampung setiap pada botol penampung.

\section{Uji Kemurnian}

Uji kemurnian fraksi aktif dilakukan menggunakan KLT dengan berbagai jenis eluen. Jika fraksi belum murni maka dimurnikan kembali dengan menggunakan teknik kromatografi kolom atau kromatografi lapis tipis preparatif.

\section{Identifikasi Isolat Aktif}

Isolat aktif yang relatif murni diidentifikasi dengan cara uji fitokimia dan dengan kromatografi gas - spektrometri massa.

\section{HASIL DAN PEMBAHASAN}

\section{Ekstraksi dan Fraksionasi}

Hasil ekstraksi total 300 gram serbuk kering iler diperoleh ekstrak kental etanol sebanyak 52,67 gram. Selanjutnya ekstrak kental ini dipartisi berturut-turut dengan nheksana, kloroform, dan etil asetat. Ekstrak kental yang diperoleh diuji bioaktivitas antibakteri dan toksisitasnya.

Hasil uji diatas menunjukkan bahwa ekstrak etil asetat mempunyai bioaktivitas antibakteri dan toksisitas yang lebih baik dibandingkan dengan ekstrak n-heksana dan kloroform.

\section{Pemisahan dan Pemurnian}

Pemisahan ekstrak kental etil asetat menggunakan kromatografi kolom dengan eluen campuran n-heksana - kloroform (6:3)
Hasil Kromatografi Kolom adalah 116 fraksi (tiap fraksi $3 \mathrm{~mL}$ ), yang selanjutnya diuji dengan Kromatografi Lapis Tipis untuk penggabungan. Fraksi-fraksi yang menampakan noda dengan pola pemisahan yang sama digabungkan, sehingga diperoleh 3 kelompok fraksi (FA, FB, FC) yang mempunyai pola pemisahan yang berbeda. Masing - masing fraksi (FA, FB, FC), diuapkan, ditimbang, diuji fitokimia serta bioaktivitas . antibakteri dan toksisitasnya. Berdasarkan uji bioaktivitas antibakteri dan toksisitasnya, fraksi FB merupakan fraksi yang memiliki bioaktivitas antibakteri dan toksisitas yang lebih baik.

Karena fraksi FB tersebut masih menghasilkan 2 noda maka fraksi FB ini kemudian di murnikan kembali dengan Kromatografi Lapis Tipis preparatif menggunakan eluen n-heksana : kloroform (6:3) sehingga memperoleh 2 fraksi yaitu $\mathrm{FB} \mid$ dan $\mathrm{FB}_{2}$. Masingmasing fraksi kemudian diuji bioaktivitas antibakteri dan toksisitasnya. Berdasarkan hasil uji diperoleh bahwa fraksi FB2 memiliki aktivitas antibakteri dan toksisitas yang lebih baik dibandingkan dengan fraksi FB).

\section{Identifikasi Senyawa Aktif}

\section{Uji Fitokimia}

Uji fitokimia terhadap fraksi $\mathrm{FB}_{2}$ pada uji flavonoid hanya positif terhadap uji dengan pereaksi bate smith-metcalve, dan negatif dengan pereaksi wilstater clan $\mathrm{NaOH} 10 \%$. Hal ini mengindikasikan bahwa fraksi $\mathrm{FB}_{2}$ diragukan mengandung senyawa flavonoid.

\section{Identifikasi dengan Kromatografi Gas - Spektroskopi Massa}

Fraksi $\mathrm{FB}_{2}$ yang diperoleh berupa padatan berwarna kuning seberat $73,6 \mathrm{mg}$. Kromatogram gas fraksi $\mathrm{FB}_{2}$ yang ditampilkan pada Gambar 1 menunjukkan adanya 4 puncak dengan waktu retensi, $t_{R}$ (menit) dan luas puncak $(\%)$ berturutturut sebagai berikut : puncak 1, tR 18,500 menit $(24,41 \%)$; puncak $2, \quad \mathrm{t}_{\mathrm{R}} 20,400$ menit $(19,53 \%)$; puncak $3, \mathrm{t}_{\mathrm{R}} 20,150$ menit $(22,95 \%)$; puncak $4, t_{R} 22,183$ menit $(33,11 \%)$; sehingga diduga fraksi $\mathrm{FB}_{2}$ mengandung 4 senyawa. 


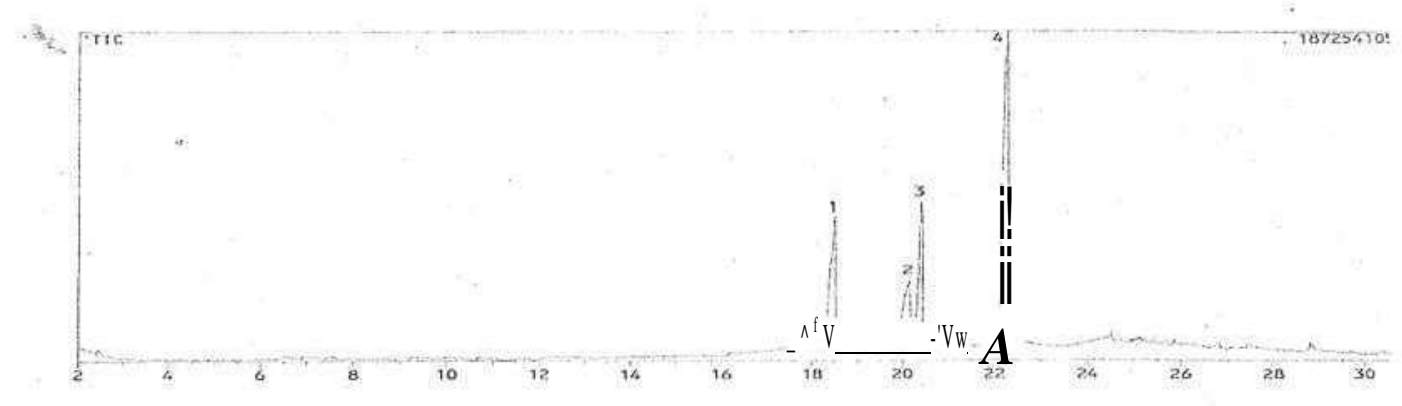

Gambar 1. Kromatogram gas fraksi FB?

\section{Identifikasi senyawa pada puncak $1 t_{R} \quad 18,500$} menit $(24,41 \%)$

Spektrum massa senyawa pada puncak 1 dan spektrum massa senyawa yang identik (Wiley 229.L) yaitu asam palmitat ditampilkan pada Gambar 2 Pada spektrum tersebut terlihat adanya ion-ion pada $\mathrm{m} / \mathrm{z} 256\left(\mathrm{M}^{+}\right)$dan $\mathrm{m} / \mathrm{z} 43$ (puncak dasar). Ion molekul $\left(\mathrm{M}^{+}\right)$pada $\mathrm{m} / \mathrm{z} 256$ mengindikasikan berat molekul 256.
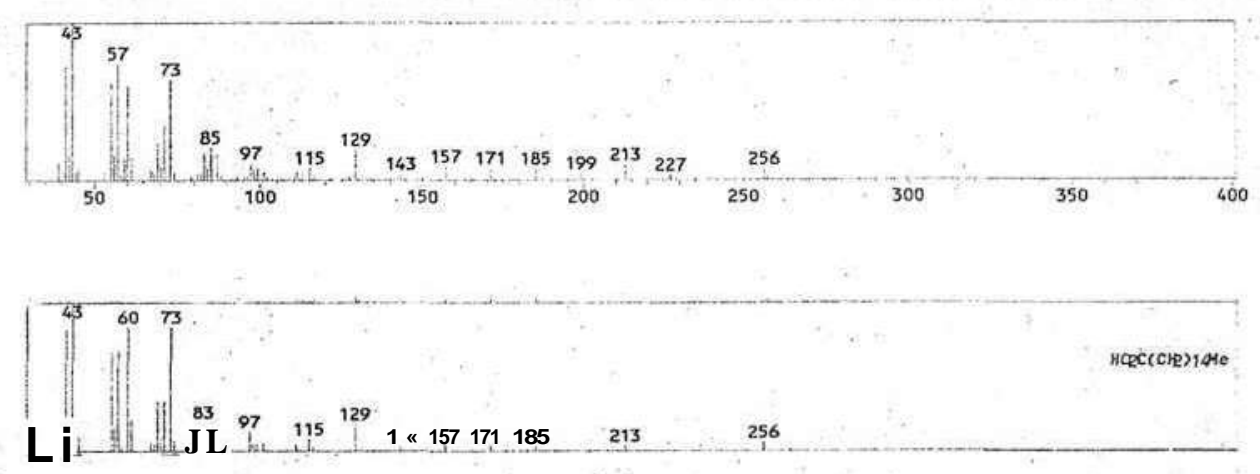

Gambar 2 Spektrum massa senyawa puncak 1 dan spektrum massa asam palmitat (Wiley 229.L)

Pola pemenggalan spektrum massa senyawa pada puncak 1 (Tabel 4.14) menunjukkan adanya pemenggalan pada $\mathrm{m} / \mathrm{z}$ 227 yang merupakan pelepasan gugus etil $\left(\mathrm{M}^{+}-\right.$ $\mathrm{C}_{2} \mathrm{H}_{5}$ ). Selain itu terlihat juga adanya pelepasan gugus metilen $\left(\mathrm{M}^{+}-14\right)$ secara berurutan dari $\mathrm{m} / \mathrm{z} 213$ sampai dengan $\mathrm{m} / \mathrm{z} 73$ yang merupakan ciri khas hidrokarbon jenuh. Adanya penggalan pada $\mathrm{m} / \mathrm{z} 73$ merupakan penggalan $\mathrm{C}_{3} \mathrm{H}_{5} \mathrm{O}_{2}{ }^{+}$.

Berdasarkan data di atas diindikasikan senyawa pada puncak 1, identik dengan asam palmitat atau asam heksadekanoat $\left(\mathrm{C}_{16} \mathrm{H}_{3} 2 \mathrm{O}_{2}\right)$ dengan struktur seperti Gambar 4.3 (Wiley 229.L).

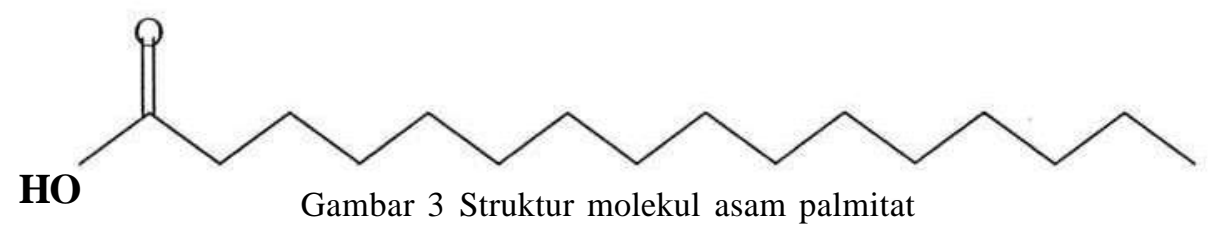

Identifikasi senyawa pada puncak $2 t_{R} \mathbf{2 0 , 4 0 0}$ menit $(19,53 \%)$

Spektrum massa senyawa pada puncak 2 dan spektrum massa senyawa yang identik (Wiley 229.L) yaitu asam stearat atau asam oktadekanoat ditampilkan pada Gambar 4. Pada spektrum tersebut terlihat adanya ion-ion pada $\mathrm{m} / \mathrm{z}$ $284\left(\mathrm{M}^{+}\right)$dan $\mathrm{m} / \mathrm{z} 59$ (puncak dasar). Ion molekul pada $\mathrm{m} / \mathrm{z} 284$ mengindikasikan berat molekul 284 

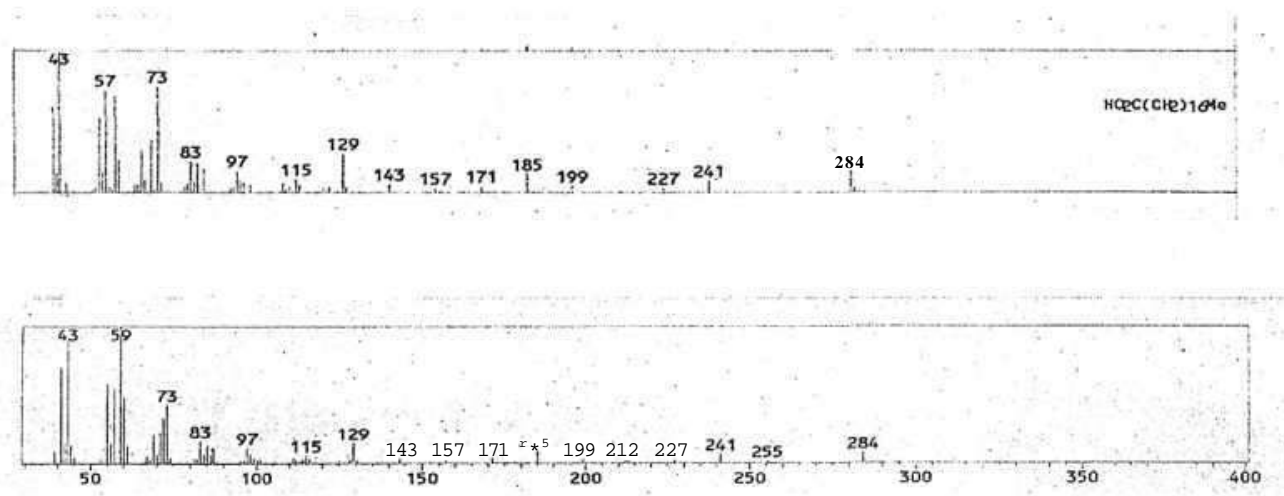

Gambar 4. Spektrum massa senyawa puncak 2 dan spektrum massa asam stearat (Wiley 229.L)

Jika dibandingkan berat molekul senyawa pada puncak 1 , berat molekul senyawa pada puncak 2 berselisih 28 satuan massa atom (sma) dan pola pemenggalan senyawa pada puncak 2 yang ditampilkan pada Tabel 4.15 mirip dengan pola pemenggalan senyawa pada puncak 1 . Dengan demikian senyawa pada puncak 2 diindikasikan suatu asam organik yang berselisih 1 gugus $\mathrm{C}_{2} \mathrm{H}_{4}$ dengan senyawa pada puncak 1 .

Berdasarkan data di atas dindikasikan senyawa puncak 2, identik dengan asam stearat atau asam oktadekanoat $\left(\mathrm{Ci}_{8} \mathrm{H}_{36} \mathrm{O}_{2}\right)$ dengan struktur seperti Gambar 5 (Wiley 229.L).<smiles>CCCCCCCCCCCCCCCCCC(=O)O</smiles>

Gambar 5. Struktur molekul asam stearat

\section{Identifikasi senyawa pada puncak $3 \mathbf{t}_{\mathrm{R}} \mathbf{2 0 , 1 5 0}$ menit $(22,95 \%)$}

Spektrum massa senyawa pada puncak 3 dan spektrum massa senyawa yang identik (Wiley 229.L) yaitu 9-oktadekenamida ditampilkan pada Gambar 4.6. Berdasarkan data dari library Wiley 229.L, 9-oktadekenamida
(C18H35NO) mempunyai berat molekul 281. Dengan demikian ion molekul senyawa pada puncak 3 adalah $\mathrm{m} / \mathrm{z} 281$. Tidak terlihatnya ion molekul senyawa pada puncak 3 kemungkinan disebabkan tidak stabilnya ion molekul tersebut $\left(\mathrm{C}_{1 \mathrm{~S}} \mathrm{H}_{35} \mathrm{NO}^{+}\right)$.

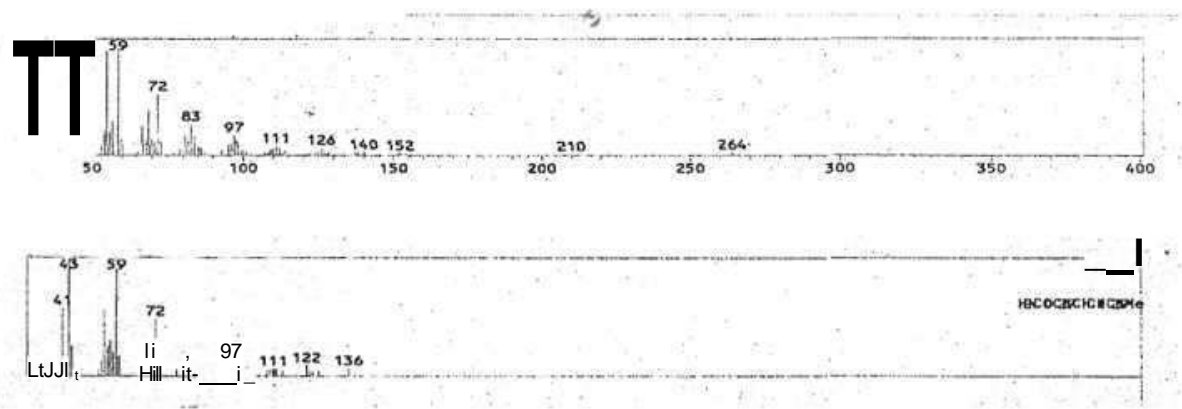

Gambar 6. Spektrum massa puncak 3 dan spektrum massa 9-oktadekenamida 
Pola pemenggalan dari spektrum massa senyawa tersebut (Tabel 4.16) menunjukkan adanya pemenggalan pada $\mathrm{m} / \mathrm{z} 59$ sebagai puncak dasar mengindikasikan adanya gugus amida. Adanya pemenggalan pada $\mathrm{m} / \mathrm{z} 59$ merupakan ciri khas amida primer rantai lurus. Penggalan ini mempakan penataan ulang McLafferty. $^{22,}$ Adanya 1 gugus amida didukung dengan berat molekul senyawa 3 yang ganjil (281) yang kemungkinan mengandung 1 atom nitrogen.

Dengan demikian berdasarkan pemenggalan seperti terlihat pada Gambar 7 dapat diindikasikan bahwa senyawa pada puncak 3 identik dengan 9-oktadekenamida $\left(\mathrm{C}_{8} \mathrm{H}_{36} \mathrm{NO}\right)$ yang struktur molekulnya seperti Gambar 7.

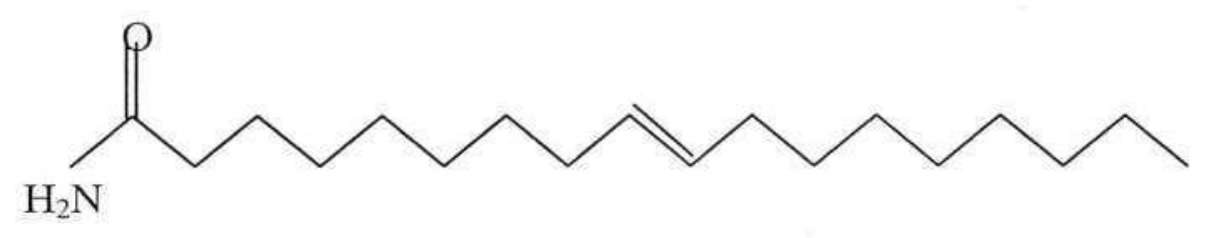

Gambar 7. Struktur molekul 9-oktadekenamida

Identifikasi senyawa pada puncak $4 \mathbf{t}^{\wedge}$ 22,183 menit $(33,11 \%)$

Spektrum massa senyawa pada puncak 4 dan spektrum massa senyawa yang identik (Wiley 229.L) yaitu ester dio'ktil heksadioat ditampilkan pada Gambar8. Berdasarkan data dari library Wiley 229.L, ester dioktil heksadioat (C22H42O4) mempunyai berat molekul 370. Dengan demikian ion molekul senyawa pada puncak 4 adalah m/z 370 . Tidak terlihatnya ion molekul senyawa pada puncak 4 kemungkinan disebabkan tidak stabilnya ion molekul tersebut (C22H42O4"'").

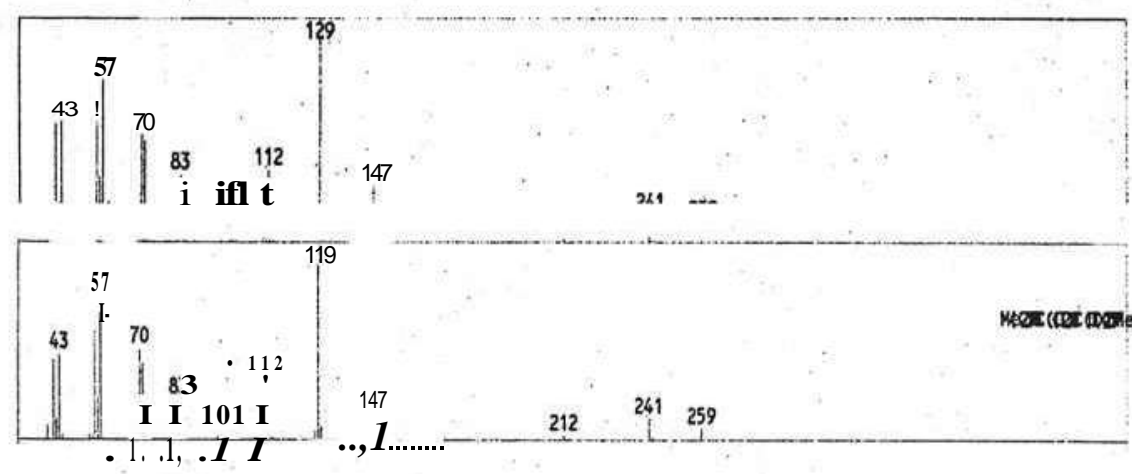

Gambar 8. Spektrum massa puncak 4 dan spektrum massa ester dioktil heksadioat (Wiley 229.L)

Pola pemenggalan spektrum massa pemenggalan pada $\mathrm{m} / \mathrm{z} 129$ merupakan senyawa pada puncak 4 yang ditampilkan pada penggalan ester oktil. Penggalan pada $\mathrm{m} / \mathrm{z} 112$ Gambar 8 menunjukkan adanya pemenggalan merupakan penggalan molekul yang melepaskan ester sebanyak 2 kali yaitu pada $\mathrm{m} / \mathrm{z} 241\left(\mathrm{M}^{+}-\quad 2\right.$ gugus ester oktil $\left(\mathrm{C}_{6} \mathrm{H}_{:, 4} \mathrm{O}_{2}\right)$. $\left.\mathrm{C}_{\mathrm{S}} \mathrm{H},{ }_{7} \mathrm{O}\right)$ dan $\mathrm{m} / \mathrm{z} 112\left(\mathrm{M}^{+}-\mathrm{C}_{16} \mathrm{H}_{34} \mathrm{O}_{2}\right)$. Adanya

ป<smiles>CCCCCCCCOC(=O)CCCCC(=O)OCCCCCCCC</smiles>

Gambar 9. Struktur molekul ester dioktil heksadioat 


\section{SIMPULAN}

Dari hasil penelitian yang diperoleh dapat diambil simpulan sebagai berikut : (1) Isolat FB2 dari daun iler bersifat antibakteri dengan luas daerah hambatan rata-rata yaitu $66,98 \mathrm{~mm}^{3}$ terhadap Micrococcus luteus dan $54,43 \mathrm{~mm}^{2}$ terhadap Eschericia coli. (2) Isolat $\mathrm{FB}_{2}$ dari daun iler bersifat toksik terhadap Artemia salina L. dengan LC50 sebesar 90,72 ppm. (3) Isolat $\mathrm{FB}_{2}$ dari daun iler diduga merupakan gabungan 4 senyawa yaitu : asam palmitat, asam stearat, 9-oktadekenamida dan ester dioktil heksadioat.

\section{UCAPAN TERIMA KASIH}

Melalui kesempatan ini penulis mengucapkan terima kasih yang setulusnya kepada semua pihak yang telah mendukung penelitian ini terutama kepada Dr. I. M. Dira Swantara, dan Dr. Yenni Ciawi.

\section{DAFTAR PUSTAKA}

Adnan, M., 1997, Teknik Kronuitografi Untuk Anal is is Bahan Makanan, Penerbit ANDI, Yogyakarta.

Colegate, Steven, M., Molyneux, Russel, J., 1993, Bioactive Natural Products : Detection, Isolation, and Structural Determination, CRC Press Inc., Boca Raton, Ann Arbor, London, Tokyo.

Darma, P. W., 2005, Penapisan, Isolasi, dan Identifikasi Senyawa yang Berpotensi sebagai Antibakteri dalam Tumbuhan Obat pada Usada Taru Premana, Skripsi, Universitas Udayana, Bali.

Harborne, J.B., J987, Metode Fitokimia: Penitntun Caret Modern Menganalisis
Tumbuhan, Diterjemahkan Oleh K. Padmawinata, ITB, Bandung, Jilid II.

Hardjono, S., 1991, Kromatografi $1^{\text {st }}$ ed. Liberty, Yogyakarta.

Keenan, C. W., Kleinfelter, D. C, Wood, J. H., 1986, limit Kimia Untuk Universitas, Diterjemahkan Oleh Rudjaatmaka, A. H., Penerbit Erlangga, edisi

Kusmardiyani, S., dan Nawawi, A., 1997, Kimia Bahan Alain, Petunjuk Laboratorium Pusat Antar Universitas, Bidang Ilmu Hayati.

Meyer, B.N., Ferrigni, N.R., and McLaughlin, 1982, Journal of Plant Medical Research, 45,31-34.

Nala N., 1993, Usada Bali, P.T. Upada Sastra, Denpasar.

Padmawinata, K., 1988, Metode Pemisahan, Penerbit ITB, Bandung.

Robinson, T., 1995, Kandungan Organik Tumbuhan Tinggi, Diterjemahkan Oleh K. Padmawinata, Penerbit ITB, Bandung.

Silverstein, R.M., Basler, G.C., \& Morril, T.C., 1991, Spectrometic Identification of Organic Compound, John Willey \& Sons, Inc., Singapore.

Srikandi, F., 1992, Mikrobiologi Pangetn, Vol.1, Gramedia, Jakarta.

Swantara, I.M.D., 2002, Studi Kandungan Senyawa Turn nan Sterol dalam Gelidium rigidum (VAHL) grev., Disertasi, Program Pasca Sarjana, Universitas Padjajaran, Bandung.

Swantara, I.M.D., 2005, Teknik Isolasi Senyawa Bioaktif dalam Tumbuhan, Workshop Pengelolaan Potensi Biodiversitas, Universitas Udayana, Bukit.Jimbaran.

Wijayakusuma, H.M.H., Dalimartha, S., Wirian, A.S., 1996, Tanaman Berkhasiat Obat di Indonesia, Pustaka Kartini, Jilid IV. 